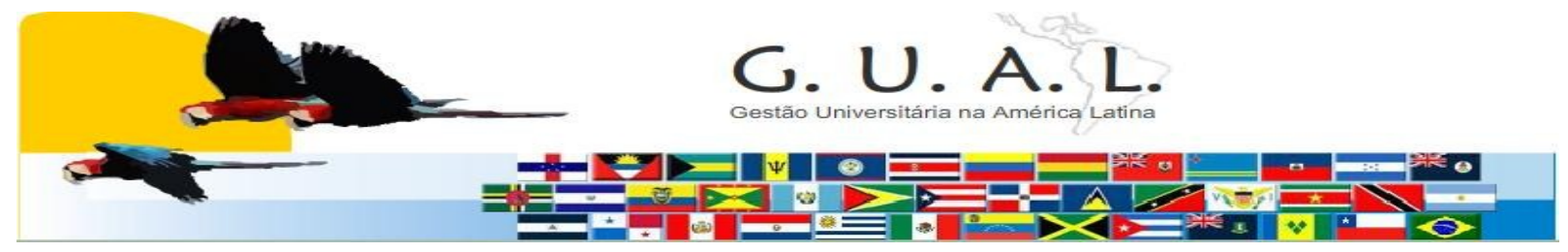

ISSN 1983-4535

\title{
ATUAÇÃO DO DEPARTAMENTO DE MARKETING EM UMA INSTITUIÇÃO DE ENSINO SUPERIOR - IES
}

\author{
José Vorlei Guimarães Martins, Bacharel \\ Centro Universitário de Lins \\ vorlei@fpte.br \\ Renato Marcelo Teixeira de Menezes, Bacharel \\ Centro Universitário de Lins \\ rmenezes@fpte.br \\ Leonides da Silva Justiniano, Doutor \\ Centro Universitário de Lins \\ leojusto@unilins.edu.br
}

\section{RESUMO}

O mercado educacional vive momentos de intensas transformações, principalmente em razão da grande concorrência do setor. O presente artigo tem por objetivo fazer uma análise geral desse mercado, evidenciando a ótica do marketing, sua importância e a necessidade de adaptação à nova economia e suas exigências. Para tal, utilizamos a metodologia da pesquisa bibliográfica e documental. Os resultados apontam para a necessidade de ações estratégicas de marketing, visando ao fortalecimento das Instituições de Ensino Superior - IES na acirrada concorrência existente no setor. Percebemos que, até a bem pouco tempo, grande parte das IES focava seus investimentos em prédios e laboratórios, sem a devida preocupação de identificar as expectativas e desejos dos alunos e as exigências do mercado. Concluímos que a nova realidade exige, hoje, um posicionamento transparente e que a reputação da marca e os valores a ela agregados ganham cada vez mais importância, o que implica no desenvolvimento de ações internas e externas, dentro de uma óptica que classifica o aluno como cliente, não apenas como estudante.

Palavras-chave: Educação. Marketing. Mercado. Ensino. IES. 


\section{ATUAÇÃO DO DEPARTAMENTO DE MARKETING EM UMA INSTITUIÇÃO DE ENSINO \\ SUPERIOR - IES}

\section{INTRODUÇÃO}

Nunca se falou tanto sobre educação, sua precariedade e a necessidade de uma política emergencial de investimentos para não comprometer o futuro do Brasil.

Apesar dos avanços dos últimos anos, há, ainda, uma enorme distância entre o real e o ideal. De forma errada, o país investe mais no ensino público universitário que no ensino fundamental e médio, mesmo consciente de que o problema maior reside na educação básica, da pré-escola ao primeiro grau, onde o estímulo ao aprendizado deveria ser maior. No Brasil, $38 \%$ da população concluíram o ensino fundamental, contra $45 \%$ do México e $56 \%$ da Argentina. O relatório Educação para Todos, divulgado em 19 de janeiro de 2010 pela Organização das Nações Unidas para Educação, Ciência e Cultura, mostra que a baixa qualidade do ensino nas escolas brasileiras exclui milhares de crianças e coloca o País na $88^{\mathrm{a}}$ posição no Índice de Desenvolvimento Educacional (IDE), atrás de países mais pobres como Paraguai, Equador e Bolívia.

Números do IBGE apontam que, apesar de dobrar o número de jovens na universidade, entre 1998 e 2008, o Brasil ainda está distante da média dos países desenvolvidos. A taxa, de $6,9 \%$, passou para $13,9 \%$ e o índice de brasileiros que freqüentam uma instituição de ensino superior é de 30\%, segundo números da Unesco. Esse cenário, por pior que pareça, aponta uma excelente oportunidade para grandes investidores que transformaram o segmento num imenso campo de batalha entre especuladores em busca de fusões, e nem sempre preocupados com a qualidade do ensino.

A concorrência entre as instituições, nem sempre saudável e leal, tem sido motivo de preocupação dos administradores educacionais que, com um enorme atraso, buscam no marketing um caminho para se desviar das dificuldades impostas por um público cada vez mais exigente. O grande problema é que o marketing é interpretado de maneira errada. Confundido com propaganda e publicidade, acaba se transformando em campanhas sazonais, apenas para captação de novos alunos.

Se levarmos em conta as diversas definições de marketing, ainda há muito que aprender por parte das instituições e seus gestores.

"Marketing é uma função organizacional e um conjunto de processos para criar, comunicar e entregar valor aos consumidores, bem como gerir a relação entre eles, a fim de beneficiar a organização e seus constituintes.” American Marketing Association (2005). 


\section{ATUAÇÃO DO DEPARTAMENTO DE MARKETING EM UMA INSTITUIÇÃO DE ENSINO SUPERIOR - IES}

Phillip Kotler (2000), um dos mais renomados autores de marketing, resume da seguinte forma: "Marketing é um processo social e gerencial através do qual indivíduos e grupos obtêm o que necessitam e desejam por meio da criação e troca de produtos e valores com outras pessoas".

Segundo Raimar Richers (1978), "Marketing são as atividades sistemáticas de uma organização humana, voltada para a busca e realização de trocas com seu meio ambiente, visando benefícios específicos".

"Marketing é a função da empresa que tem por objetivo conquistar e preservar clientes.” (DRUCKER; PETER, 1954). Porém, o autor foi feliz ao definir que o "objetivo do Marketing é tornar a venda supérflua, é conhecer e compreender o cliente tão bem, de modo que o produto ou serviço se ajuste e venda por si próprio. (1973)"

O conceito do autor brasileiro Marcos Cobra (1992) é "Marketing é mais do que uma forma de sentir o mercado e de adaptar produtos ou serviços; é um compromisso com a busca da melhoria da qualidade de vida das pessoas. Neste sentido, a extensão da atividade de venda assume um novo papel: o de preservar e aumentar o bem-estar do consumidor e da sociedade".

Diante das definições acima, podemos inferir que o marketing é o dever de casa das empresas para identificar o que as pessoas precisam e o que elas podem oferecer, de que forma, como, quando e onde.

Se na velha economia o marketing era voltado para o produto, hoje, necessariamente, seu foco são os clientes. Essa é a conclusão de Philip Kotler (1998), reforçando que o Marketing, como nós o conhecemos hoje, está morto e acabado.

Em resumo, as empresas devem observar com cuidado o novo mundo, baseado na internet, em que convergem para lá todas as tribos, dos mais jovens até os mais velhos, em busca de um relacionamento virtual distante da insegurança do mundo real. Sem citar os diversos outros benefícios advindos dessa ferramenta.

\section{O MERCADO EDUCACIONAL NO BRASIL}

No cenário do ensino superior nacional, há excesso de oferta de cursos e vagas ao que podemos classificar como mercado educacional, principalmente nas IES privadas com autonomia para criação de novos cursos. 


\section{ATUAÇÃO DO DEPARTAMENTO DE MARKETING EM UMA INSTITUIÇÃO DE ENSINO SUPERIOR - IES}

O ingresso de calouros mal preparados na graduação é outro fator que deve ser observado pelos governos, como forma de melhorar o nível dos egressos.

A exigência do MEC para que as IES tenham em seus quadros um percentual maior de mestres e doutores, não refletiu diretamente na melhoria do ensino. Muitos docentes, por mais titulações que possuem, desconhecem a prática da profissão e, portanto, sentem dificuldade de apresentar exemplos que possam ser melhor entendidos pelos alunos. De outra forma, há os que não possuem habilidades pedagógicas para transmitir as informações com facilidade.

Estes e outros são fatores decisivos na influência das ações estratégicas de marketing para garantir a sobrevivência das instituições.

Além da concorrência e da mercantilização da educação, diversos fatores devem ser considerados para a manutenção da saúde financeira das universidades, conforme seguem abaixo:

- Convivência entre universidades públicas e universidades privadas.

- Guerra de preço nas mensalidades.

- Baixa capacidade de pagamento por parte da demanda discente e conseqüente aumento da inadimplência e evasão.

- Gestão despreparada para atuar em um ambiente com forte concorrência.

- Diferença entre a demanda de final de ano e demanda do meio do ano.

- Baixa qualidade dos cursos.

- Concorrência com Instituições públicas que carregam fama de centros de excelência na produção do conhecimento e a custo zero para o aluno.

- Baixa remuneração de professores pelas instituições, pressionadas pelos custos da concorrência.

- Professores com mestrado e doutorado, porém, sem a experiência necessária para transmitir a realidade de mercado.

- Alunos egressos do ensino público sem uma base adequada que os permita dar seqüência aos estudos em nível de graduação.

- Surgimento de universidades corporativas sob a tutela de grandes empresas.

- Ausência de um projeto de sustentabilidade que sai do papel à prática.

É fundamental que todos se conscientizem de que o trabalho desenvolvido na instituição, independentemente do local ou departamento, possui um único objetivo: a satisfação do aluno. Para perseguir o aumento do índice de satisfação, é necessário que sejam revistos todos os processos internos e identificadas as falhas, redesenhando o que for necessário (LAS CASAS, Alexandre Luzzi, 2008).

Percebe-se que na educação muitas mudanças ocorreram: lousas mágicas, 
computadores, equipamento multimídia, laboratórios modernos, novas práticas pedagógicas, porém, os clientes continuam recebendo o mesmo atendimento de antes, com frieza e sem a atenção adequada a quem, de verdade, mantém a escola.

Dessa forma, o sucesso no mercado educacional dependerá de uma visão estratégica, que considere o aluno como cliente - com regras a seguir - e que, portanto, admita a educação como um serviço que segue leis de mercado e está sujeita às mesmas instabilidades dos diversos segmentos.

\section{O MERCADO REGIONAL}

Tomando por base a região Noroeste Paulista, num raio de até $100 \mathrm{~km}^{2}$ da cidade de Lins, nos referimos a uma das regiões mais pobres do estado de São Paulo.

Nesse perímetro, concorrem no segmento educacional 26 IES que ofertam, em média, 25 mil vagas, sem contar os cursos de educação a distância - EAD.

Outro dado complicador que afeta a região é o registro da queda de $6 \%$ no número de matrículas, entre 2008 e 2010, na região de Marília. Por outro lado, contrapondo esse cenário, de 2000 a 2009, o número de cursos cresceu 95\%. A informação está na Revista Ensino Superior, do Sindicato das Entidades Mantenedoras de Estabelecimentos de Ensino Superior no Estado de São Paulo - SEMESP, edição número 153, de junho de 2011.

\section{PRINCIPAIS ERROS OU PROBLEMAS DAS IES}

São vários os fatores que interferem nos processos de captação e retenção de alunos. Alguns, se interpretados e tratados adequadamente, refletirão diretamente no investimento para as campanhas de vestibular que, até então, representam custo maior ao priorizar a captação, ao invés da retenção de alunos.

Aluno ou Cliente: Muitos gestores e professores ainda relutam em aceitar o aluno como cliente, na ótica do marketing. Para eles, o discente nada mais é que um cumpridor de deveres que deve, basicamente, aceitar o processo ensino/aprendizagem tendo o docente como ser intocável, a frente de todas as atividades pedagógicas.

Neste aspecto, não se trata de "passar a mão" na cabeça do aluno e facilitar-lhe a vida acadêmica. Escola e aluno têm regras específicas a cumprir dentro do contexto educacional. 
Relacionamento interno: há necessidade de se definir o cliente/aluno como prioridade e melhorar cada vez mais o relacionamento com ele.

Faz parte desse contexto, a atualização de todos os processos internos, desde o atendimento da secretaria acadêmica e biblioteca, até o dia-a-dia em sala de aula. Definir o calendário escolar priorizando o horário do professor é um erro dos mais comuns nas IES.

Avaliação Institucional/Ouvidoria: São dois importantes canais receptores de informações vindas da comunidade acadêmica, com o objetivo principal de medir o grau de satisfação com o serviço que a instituição oferece.

O primeiro deles, a Avaliação institucional, uma exigência do MEC, "proporciona que a instituição construa conhecimentos sobre si mesma, mantendo a referência do compromisso e da responsabilidade com a formação adequada de profissionais que atuarão em diferentes áreas e atividades humanas" (www.unilins.edu.br/avaliacaoinstitucional).

O segundo, da própria instituição, acessado via site ou pessoalmente, é um canal livre para expressão da comunidade acadêmica que reúne críticas, elogios e sugestões para análise e providências por parte da diretoria.

Por mais importantes e necessários que sejam, não terão valor algum se não houver resposta rápida aos anseios da comunidade acadêmica. Oferecê-los apenas para cumprir exigências legais não garante o cumprimento de suas reais finalidades.

Identificação do professor com a instituição: É comum encontrarmos docentes lecionando em várias IES, seja em razão do reconhecimento profissional que conquistaram, seja em função da escassez de professores em determinadas áreas. Independentemente da situação, o que se percebe é a falta de identificação desse profissional com a filosofia da escola. O reflexo é negativo a partir do momento em que o docente se mostra indiferente aos objetivos da marca e se torna um embaraço no processo de relacionamento com a comunidade acadêmica.

Baixa capacidade de investimento: É perceptível a falta de condições financeiras ou de planejamento de algumas IES, no que se refere a manutenção de um plano de comunicação institucional para reforço da imagem da marca. Observam-se, principalmente, ações sazonais 


\section{ATUAÇÃO DO DEPARTAMENTO DE MARKETING EM UMA INSTITUIÇÃO DE ENSINO SUPERIOR - IES}

para divulgar as campanhas vestibulares, normalmente em períodos de grande disputa por espaços publicitários, tornando quase que imperceptíveis as campanhas com investimento acanhado.

Também faltam recursos para manter projetos esportivos ou culturais que possibilitam maior relacionamento com os estudantes do ensino médio, principal público-alvo das IES.

\section{ATUAÇÃO DO DEPARTAMENTO DE MARKETING EM UMA IES}

A partir da crescente expansão do mercado educacional no Brasil, muitas instituições perceberam a necessidade de contar com o permanente apoio de um departamento de marketing, seja ele próprio, definido como House Agencies $^{1}$, ou de uma agência de publicidade terceirizada que pudesse direcionar melhor suas ações, como forma de se diferenciar entre os concorrentes.

Ainda assim, as atividades desses profissionais, na maioria delas, ficaram limitadas a campanhas sazonais, visualizadas somente em períodos pré-vestibulares, quando, o ideal, seria a adoção de um planejamento maior, que contemplasse também a comunicação institucional para reforço da marca.

Dentre as estratégias que consideramos importantes para uma IES, destacamos as seguintes:

- Marketing de Relacionamento -equipes que visitam as escolas do Ensino Médio e cursinhos, falando diretamente com seu target $^{2}$, em salas de aulas. Discorrem sobre o processo seletivo, sorteiam brindes e convidam os alunos para participarem de oficinas vocacionais.

- Oficinas Vocacionais - oferecer aos alunos uma atividade coordenada por uma Psicóloga, dando a eles a oportunidade de identificarem sua vocação. Pode ser realizada no próprio campus, quando os participantes terão a possibilidade de uma visita aos principais laboratórios da instituição.

- Aulas Abertas - possibilitar aos candidatos ao processo seletivo o agendamento uma aula do curso de seu interesse, como forma de ajudá-los a conhecerem melhor a estrutura do curso e a profissão.

- Redes Sociais - sob a coordenação do Departamento, participar das principais plataformas de redes sociais, Twitter, Facebook e Orkut, mantendo maior interação e proximidade com o público desses canais.

\footnotetext{
${ }^{1}$ House Agencie: agência da casa que atende exclusivamente uma determinada empresa ou instituição.

2 Target: público-alvo.
} 
- Marketing Social - utilizar a estrutura de cada curso da IES e realizar ações junto a comunidade, como, por exemplo, medição de pressão arterial ou massa corpórea, pelo curso de enfermagem, e outros eventos relacionados às diversas áreas de atuação.

- Feiras de Vestibulares - diversas cidades da microrregião realizam feiras de vestibulares para seus alunos e convidam alunos de outras instituições. A presença da IES é importante, levando-se em conta a questão financeira e logística, bem como o potencial dessas cidades no número de matrículas.

Todas essas ações, devidamente distribuídas num planejamento maior, e integradas com várias outras estratégias, podem possibilitar um crescimento anual consistente e importante.

Investir em captação é necessário, porém, todo esforço terá sido em vão se não houver uma política estratégica de relacionamento que assegure a permanência do aluno na instituição ao longo do curso.

Fatores financeiros, mudanças, opção errada, aprovação em outros vestibulares, são algumas das razões que explicam a evasão. Porém, o mais preocupante e não menos desconhecido, são as reclamações sobre o curso, ausência do coordenador, professores que não conseguem transmitir o conteúdo, entre outras.

Todas essas razões devem ser analisadas com muito cuidado e amplamente discutidas, não apenas com o objetivo de se confirmar ou discordar das alegações discentes, mas, como base para definição de uma política adequada para identificação e eventual retroação do processo de evasão.

\section{MIX DE MARKETING}

No livro Marketing Educacional, edição de 2007, Las Casas aponta que, na maior parte das escolas, o Departamento de Marketing não tem autonomia sobre todos os compostos do mix de marketing, estando restrito apenas ao que se refere à Promoção. Abaixo seguem algumas considerações a respeito de cada um dos P's do mix e as razões que acreditamos justificar essa limitação.

Produto: no caso das IES, trata-se da prestação de serviços educacionais, é definido por suas próprias regras e, portanto, sem a influência do Departamento de Marketing. 


\section{ATUAÇÃO DO DEPARTAMENTO DE MARKETING EM UMA INSTITUIÇÃO DE ENSINO SUPERIOR - IES}

Preço: esta variável pode ser considerada um importante diferencial competitivo e passível da participação do Marketing na sua composição. Levando-se em conta que, no Brasil, apenas 25\% dos alunos matriculados em IES conseguem terminar seus estudos sem atrasar o pagamento (LAS CASAS, 2007), o ideal é que a mensalidade seja proporcional à realidade local, equalizando custo/qualidade.

Nas IES, além dos descontos advindos dos convênios com os governos estadual e federal, é necessário analisar a possibilidade parcerias empresariais, com descontos progressivos de acordo com o número de alunos matriculados.

Praça: algumas instituições conseguem espalhar pontos de inscrição vestibular em outras cidades, em shoppings, ruas de grande fluxo ou eventos, o que pode ser considerada uma estratégia de distribuição.

Porém, a efetiva distribuição de serviços educacionais ocorre com a abertura de estabelecimentos no mercado visado (LAS CASAS, 2008).

Promoção: este é o composto em que o Departamento de Marketing da maioria das IES tem autonomia para desenvolver o planejamento e criação. O orçamento é definido pela diretoria, estabelecido a partir da análise financeira da instituição.

Além dos tradicionais 4 P's do Marketing, no que se refere ao segmento educacional que atua na prestação de serviços, podemos incluir o quinto $\mathrm{P}$, de Professor, ou de pessoas. Aliás, se o objetivo for melhorar o relacionamento com o aluno, este será, sem dúvida, o principal componente do mix de marketing educacional a ser trabalhado.

De todas as formas de abordagem direta ao aluno, nenhuma é tão eficiente quanto o professor. Em sala de aula, ele é a própria instituição.

A participação dos professores nos processos de captação ou manutenção de alunos pode ser bem maior e, além de integrar as estratégias do plano de marketing estabelecido para divulgação das campanhas vestibulares, sua atuação neste sentido deve se sustentar ao longo de toda a sua permanência nos quadros docentes da instituição.

Para que ação do professor colabore efetivamente no relacionamento com os alunos, faz-se necessário mudar a postura de alguns deles que insistem em atuar de forma soberba, interferindo e desrespeitando o espaço e a importância discente no contexto universitário. 


\section{ATUAÇÃO DO DEPARTAMENTO DE MARKETING EM UMA INSTITUIÇÃO DE ENSINO SUPERIOR - IES}

\section{EDUCAÇÃO A DISTÂNCIA}

A crescente busca pela educação coloca a comodidade como um diferencial a ser cuidadosamente observado pelas instituições de ensino. Daí a importância de adaptar os serviços educacionais para cada tipo de público. Las Casas (2007) cita o Ensino a Distância (EAD) como exemplo, preferido pelas empresas como forma de capacitar seus executivos que não dispõem de tempo para cursar um programa regular. Além da otimização do tempo há uma considerável redução nos custos de treinamento.

Por outro lado, o EAD também cresce no Ensino Superior, para cursos de graduação e até de pós-graduação, ofertados de forma integral semipresenciais, com oferta de $20 \%$ das disciplinas, conforme legislação vigente (MEC/Portaria n. 4.059, de 10 de dezembro de 2004.).

Ainda que cursar uma graduação ou pós a distância traga flexibilidade de tempo e local de estudo para o aluno, pesquisas apontam a dificuldade do aluno em manter os estudos, o que tem elevado os índices de evasão (FAVERO \& FRANCO, 2006).

\section{CONCLUSÃO}

Orientar as ações de marketing apenas para o produto, ainda que seja especificamente para a qualidade do curso, não é a melhor estratégia. Se levarmos em conta que um dos princípios básicos do marketing é o relacionamento, faz-se necessário contato freqüente de funcionários e professores com pais ou responsáveis pelos discentes, estabelecendo harmonia e melhorando o nível de satisfação do alunado. Sem se desviar do foco principal, que é a formação dos alunos, é preciso prepará-los para a obtenção de empregos ou concursos, o que também representa uma importante forma de divulgação.

Outra forma de buscar a satisfação dos clientes é melhorando os processos internos para atender rapidamente às necessidades dos alunos no que se refere a informações ou fornecimento de documentos. Se a instituição detém todas as informações do aluno, não se podem conceber processos internos tão demorados.

Outro público que deve receber o mesmo tratamento são os ex-alunos. Já posicionados no mercado podem se configurar em excelentes parceiros não só para a colocação dos recémformados, mas, também, na transmissão da experiência prática adquirida ao longo do desempenho da profissão, através da oferta de estágios, palestras e encontros profissionais 
programados pela própria escola. Na Europa, cresce o número de doações efetuadas por exalunos que alcançaram sucesso na vida profissional, como reconhecimento da importância da escola na sua formação. Além disso, este mesmo segmento é um cliente potencial para a oferta de cursos de pós-graduação.

A preocupação com o meio ambiente é outro tema que não pode mais ficar fora das discussões que balizam o planejamento da Instituição ou o seu Projeto de Desenvolvimento Institucional - PDI.

O tema sustentabilidade, que perturba a todos, confere ao marketing a responsabilidade de aproximar a escola às questões ambientais e transferir ao público-alvo o benefício emocional da marca. O neoconsumidor, ávido por novidades e produtos que se assemelham a sua personalidade, dá preferência pelas marcas preocupadas com o meio ambiente.

Finalizando, a prospecção de novos alunos é necessária, mas não deve ser prioridade. Se um aluno matriculado na graduação permanecerá na escola por um período médio de quatro anos, trabalhar o relacionamento com quem já está cursando é sempre muito mais fácil e objetivo e, comprovadamente, de menor custo. E o mais importante é que o depoimento de um cliente representa um significado maior pela comprovação de sua satisfação com a instituição.

\section{REFERÊNCIAS BIBLIOGRÁFICAS}

Sites:

http://www.estadao.com.br/noticias/suplementos,dobra-n-de-jovens-na-universidade. http://www.atarde.com.br/brasil/noticia.jsf?id=1345431

http://www.unilins.edu.br/avaliacao/index.php

BASTOS, Marcos \& BRAGA, Ryon. Marketing educacional: ferramentas de gestão para instituições de ensino. São Paulo: Cobra Editora e Marketing \& Hoper Editora, p. 9, 2004.

COBRA, Marcos. Administração de Marketing. 2. ed. São Paulo: Atlas, 1992.

COLOMBO, Sonia S. ET. AL. Marketing educacional em ação. Porto Alegre: Artmed Editora, 2005.

COSTA, José da. Modelos de Educação Superior a Distância e Implementação da 
Universidade Aberta do Brasil. Revista Brasileira de Informática na Educação V. 15 N. 2 - Maio a Agosto, 2007.

FAVERO, Rute Vera Maria; FRANCO, Sérgio Roberto Kieling. Um estudo sobre a permanência e a evasão na Educação a Distância. Revista Novas Tecnologias na Educação - V. 4 N.o 2 - Dezembro, 2006.

KOTLER, Philip e KELLER, Kevin. Administração de Marketing - $12^{\text {a }}$ Edição. São Paulo: Prentice Hall, 2006.

KOTLER, Philip. Administração de Marketing: a edição do novo milênio. $10^{a}$ ed. São Paulo. Prentice Hall, 2000.

Gazeta Mercantil/Caderno C - Pág. 2. José Eustachio - Sócio-diretor da Talent.

LAS CASAS, Alexandre. Administração de marketing: conceitos, planejamentos e aplicações à realidade brasileira. São Paulo: Ed. Atlas, 2006.

LAS CASAS, Alexandre. Marketing Educacional: da educação infantil ao ensino superior no contexto brasileiro. São Paulo: Saint Paul Editora, 2008.

Revista Comemorativa 20 anos da Fundação Paulista de Tecnologia e Educação. Março, 1084.

RICHERS, R., Ensaios de Administração Mercadológica, 2a edição revista e ampliada, FGV, Rio de Janeiro, 1978. [pág. 107]. 


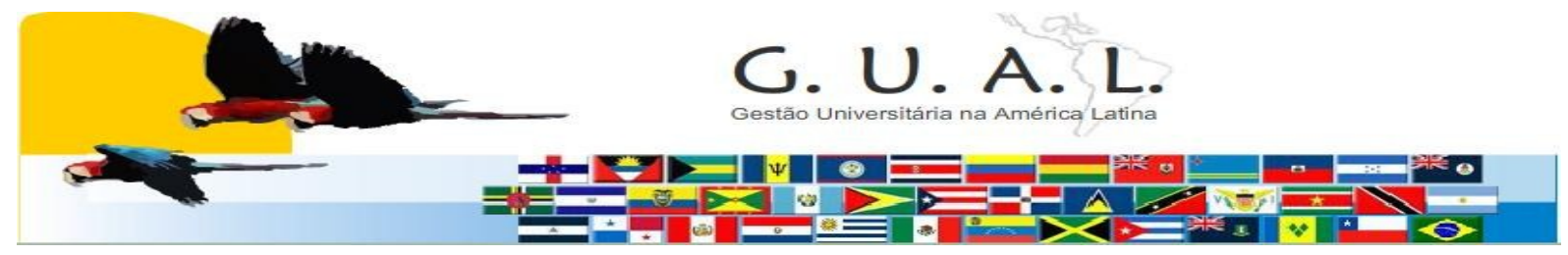

ISSN 1983-4535

\title{
THE ROLE OF THE MARKETING DEPARTMENT IN HIGHER EDUCATION INSTITUTIONS - HEIS
}

\author{
José Vorlei Guimarães Martins, Bacharel \\ Centro Universitário de Lins \\ vorlei@fpte.br \\ Renato Marcelo Teixeira de Menezes, Bacharel \\ Centro Universitário de Lins \\ rmenezes@fpte.br \\ Leonides da Silva Justiniano, Doutor \\ Centro Universitário de Lins \\ leojusto@unilins.edu.br
}

\begin{abstract}
The education market has been experiencing moments of intense changes, mainly due to the fierce competition in the industry. This article aims to make a general analysis of this market, showing the perspective of marketing, its importance and the need to adapt to the new economy and its requirements. For such purpose, we use the methodology of documentary and bibliographical research. The results indicate the need of strategic marketing actions, which aims to strengthen higher education institutions - HEIs in the fierce competition in the sector. We realize that until very recently, most of the HEIs focused their investments in buildings and laboratories, without due concern to identify the expectations and desires of students and the demands of the market. We conclude that, nowadays, the new reality requires clear positioning and that the brand reputation and value added to it are becoming increasingly important, which implies the development of internal and external actions, within a perspective that classifies the student as a client, not just as a student.
\end{abstract}

Keywords: Education. Marketing. Market. Education. HEIs. 